\title{
Testing the Rio Doce as a riverine barrier in shaping the Atlantic rainforest population divergence in the rodent Akodon cursor
}

\author{
Victor Hugo Colombi, Silvia Ramira Lopes and Valéria Fagundes \\ Departamento de Ciências Biológicas, Centro de Ciências Humanas e Naturais, \\ Universidade Federal do Espírito Santo, Vitória, ES, Brazil.
}

\begin{abstract}
Akodon cursor occurs in dense rainforest from northern $\left(8^{\circ} \mathrm{S}\right)$ to southern $\left(26^{\circ} \mathrm{S}\right)$ states along the Atlantic coast of Brazil. Previous karyological and molecular data revealed two major clades, one including northern $\left(8-15^{\circ} \mathrm{S}\right)$ and the other southern $\left(19-26^{\circ} \mathrm{S}\right)$ populations. The center of geographic distribution $\left(15-20^{\circ} \mathrm{S}\right)$, which included the state of Espírito Santo, was identified as a potential vicariance region. Since river barriers are among the most discussed models in the study of Neotropical diversification, we examined whether the Rio Doce $\left(19^{\circ} \mathrm{S}\right)$ plays an important role in shaping the population genetic divergence of $A$. cursor by including samples from Espírito Santo in the analysis. Our results showed that the northern-southern division region in Atlantic forest was no coincidence with the presence of the Rio Doce by refuting the hypothesis that this river is an effective barrier to gene flow between populations. Instead, we found evidence that isolation by geographical distance shaped the phylogeographical structure in the southern lineage. However, there is uncertainty about effectiveness of the processes involved and further studies based on wider sampling are needed.
\end{abstract}

Key words: Akodontini, Atlantic Forest, cytochrome b, gene flow, phylogeography, Rodentia.

Received: October 9, 2009; Accepted: July 8, 2010

Originally extending for $1,300,000 \mathrm{~km}^{2}$ along the Brazilian coast and reaching into Paraguay and Argentina, the Atlantic forest has been reduced to less than $8 \%$ of its range (Gusmão Câmara, 2003). This habitat loss has been closely linked to fragmentation but the region still harbors one of the highest percentages of endemic species in the world, with many species and even genera of vertebrates still being described (Rodrigues, 2005). Studies of the complex evolutionary history of this habitat have identified northern and southern components in the Atlantic Forest, with genetically structured populations and the differentiation of distinct groups throughout the Atlantic biome (Mustrangi and Patton, 1997; Costa et al., 2000; Geise et al., 2001; Pellegrino et al., 2005; Cabanne et al., 2007; Nogueira and Fagundes, 2008). These findings suggest that a common mechanism may have played a role in shaping the distributions of multiple taxa in this biome. Among several hypotheses for the diversification of rainforest biotas (Moritz et al., 2000), evolution in palaeorefuges (Carnaval and Moritz, 2008; Thomé et al., 2010) and the influence of geographical barriers (Pellegrino et al., 2005; Cabanne et al., 2007) are the two most commonly invoked mechanisms.

Send correspondence to Valéria Fagundes. Laboratório de Genética Animal, Departamento de Ciências Biológicas, Centro de Ciências Humanas e Naturais, Universidade Federal do Espírito Santo, Av. Fernando Ferrari 514, Goiabeiras, 29075-010 Vitória, ES, Brazil. E-mail: vfagunde@pq.cnpq.br.
The rodent Akodon cursor Winge, 1887 (Cricetidae) is widely distributed in rainforest along the Atlantic coast of Brazil (Musser and Carleton, 2005), from the northern states of Paraíba and Pernambuco $\left(8^{\circ} \mathrm{S}\right)$ through Bahia, Espírito Santo, Rio de Janeiro, Minas Gerais and São Paulo to the northern region of Paraná state in the south $\left(26^{\circ} \mathrm{S}\right)$. This species has a peculiarly high karyotypic variability, with the diploid number varying from $2 \mathrm{n}=14$ to 16 and fundamental numbers (FN) ranging from 18 to 26 (Fagundes et al., 1998). Although there is no geographic structuring of this karyological diversity, molecular studies revealed a well-structured organization of genetic diversity of mtDNA into two major clades in Atlantic forests (Nogueira and Fagundes, 2008). These authors proposed that the diversification of populations in this species was shaped by a putative geographic barrier instead of a reproductive barrier created by errors in chromosomal pairing. This suggestion was apparently supported by the fact that the $2 \mathrm{n}=14$, $2 \mathrm{n}=15$ and $2 \mathrm{n}=16$ karyotypes were equally distributed in both lineages.

By analyzing the overall geographic distribution of $A$. cursor, Nogueira and Fagundes (2008) proposed that the observed genetic variation followed the central-marginal model in which the highest genetic variability occurs in the center and declines towards the edges of the range. In their study, peripheral populations from northern and southern lineages showed the lowest intra-populational genetic di- 
versity whereas central populations from Espírito Santo had the highest such diversity. Based on this finding, Nogueira and Fagundes (2008) suggested the existence of a contact zone between northern and southern lineages somewhere in the area of the Rio Doce basin (north of Espírito Santo), and that new samples from this region should be included in future studies.

The aim of the present work was therefore to examine the partitioning of genetic variability in $A$. cursor by including mainly samples from Espírito Santo in order to determine whether the Rio Doce is as an effective barrier for gene flow, thereby stimulating population divergence. For this, we included samples from the north and south of the Rio Doce basin that had never been tested in previous studies. Samples from São Paulo (southern lineage) and Bahia (northern lineage) were used to represent the two major lineages previously observed and to help polarize the analysis.

DNA was extracted from samples of frozen muscle or liver obtained from 64 specimens of $A$. cursor collected at 10 spawning sites in three states with Atlantic rainforest: Bahia $(\mathrm{n}=10)$, Espírito Santo $(\mathrm{n}=48)$ and São Paulo $(\mathrm{n}=5)$ (Table 1, Figure 1), as described by Bruford et al. (1992). Upon extraction, a $1140 \mathrm{bp}$ fragment of mitochondrial DNA containing the cytochrome-b (Cyt-b) gene was amplified using the primers described by Smith and Patton (1993). The amplifications were done in a $25 \mu \mathrm{L}$ reaction volume containing 1X PCR buffer (Invitrogen), $1.0 \mathrm{mM} \mathrm{MgCl}_{2}, 0.8 \mathrm{mM}$ dNTPs, $0.2 \mathrm{mM}$ of each primer, $3.0 \mathrm{U}$ of Platinum Taq polymerase (Invitrogen) and 5-50 ng of template DNA. The thermal cycling conditions were: $94{ }^{\circ} \mathrm{C}$ for 3 min followed by 40 cycles of $94{ }^{\circ} \mathrm{C}$ for $30 \mathrm{~s}, 48^{\circ} \mathrm{C}$ for $40 \mathrm{~s}$ and $72^{\circ} \mathrm{C}$ for $90 \mathrm{~s}$, with a final extension step of $72{ }^{\circ} \mathrm{C}$ for $5 \mathrm{~min}$.

The amplicons were purified with either PureLink PCR purification kits (Invitrogen) or ExoSAP-IT ${ }^{\circledR}$ (USB Corporation), according to the manufacturers instructions, and then quantified in a NanoDrop spectrophotometer prior to cycle-sequencing. Sequencing used forward and reverse primers and was done directly in a capillary ABI3700 genetic analyser with the Big Dye Terminator protocol (Applied Biosystems). Electropherograms were inspected visually using BioEdit v. 7.09 (Hall, 1999) and alignments were done using Clustal X in MEGA v. 4 (Tamura et al., 2007).

ARLEQUIN v. 3.11 (Excoffier et al., 2005) was used to explore the genetic characteristics and partitioning of nucleotide diversity. The number of polymorphic sites and the haplotype $(h)$ and nucleotide $(\pi)$ diversity indices were computed (Nei, 1987). The appropriate model of nucleotide sequence evolution was determined using MODELTEST v. 3.7 (Posada and Crandall, 1998) and AIC parameters were chosen. Hierarchical analysis of molecular variance (AMOVA; Excoffier et al., 1992) done with ARLEQUIN v. 3.11 was used to investigate the patterns of historical population structure, with the fixation indices serving to estimate the proportion of variation within popu-

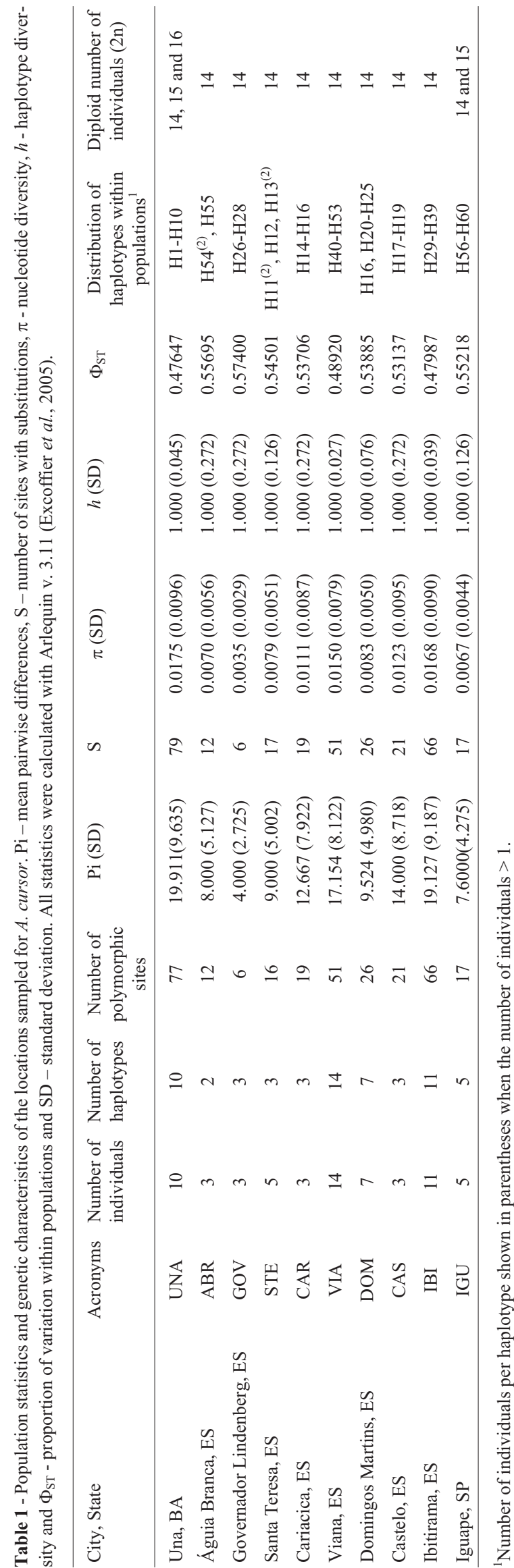




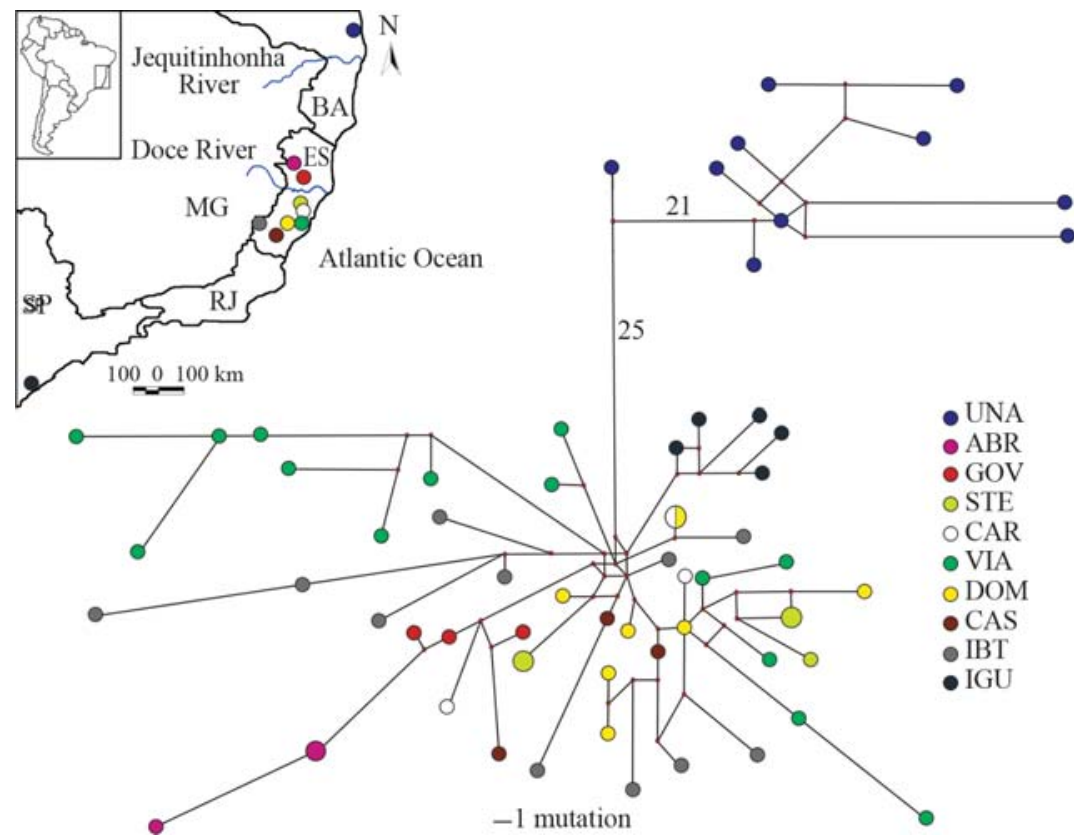

Figure 1 - Map of localities sampled for A. cursor in eastern Brazil and median-joining network of haplotypes. Circle sizes are proportional to haplotype frequency and each circle is colour coded according to the haplotype's presence at the sampling locations. Unobserved haplotypes are represented by small red circles. Branches are proportional to the number of mutations, except for those with numbers, which represent highly divergent haplotypes with more than 10 mutations. Acronyms, geographic coordinates and altitude of localities are: Bahia state, municipality of Una (UNA, $15^{\circ} 16^{\prime} \mathrm{S}, 39^{\circ} 04^{\prime}$ W, 66

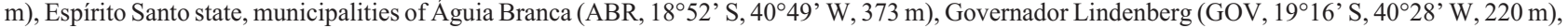

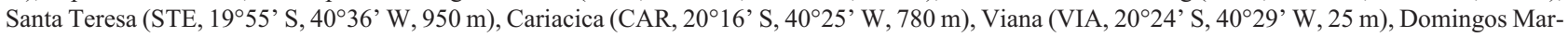

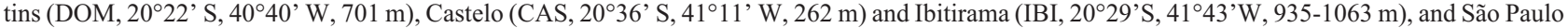
state, municipality of Iguape (IGU, $24^{\circ} 42^{\prime} \mathrm{S}, 47^{\circ} 34^{\prime} \mathrm{W}, 144 \mathrm{~m}$ ).

lations (Фst), among the groups (Фct), and among the populations within groups ( $\Phi s c)$. Pairwise $\Phi S T$ values were also generated for population comparisons. The amount of ongoing gene flow between populations was estimated using the $\Phi_{\mathrm{ST}}$ values (Hudson et al., 1992). To depict the hierarchical relationship between haplotypes that reveals the mutational steps involved in the transition of one haplotype to another, and to assess the association between haplotype and geography, a haplotype network was generated using the median-joining (MJ) algorithm (Bandelt et al., 1999) as implemented in NETWORK 4.2.0.1 (http://www.fluxus-engineering.com/sharenet.htm). Phylogenetic analyses were done using PAUP* 4.0b1 (Swofford, 2003) with maximum-parsimony (MP). Support for individual clades was evaluated using bootstrap re-sampling (Felsenstein, 1985) with 1000 replications of random addition and tree bisection reconnection (TBR) branch swapping.

Sixty haplotypes from 64 individuals were detected across all populations (Table 1). Of 1140 sites, 205 were polymorphic, with high haplotype and low nucleotide diversity indices in all populations. There was high haplotype diversity $(h)$ and low nucleotide diversity, such as is frequently encountered in populations undergoing a population bottleneck followed by demographic expansion, with the accumulation of mutations (Grant and Bowen, 1998). This feature could explain the high number of polymorphic sites and is not uncommon in Atlantic Forest species.
The MP tree topology (data not shown) and median-joining network (Figure 1) showed two major divergent lineages. The ten haplotypes of the 10 individuals from the northern lineage occurred in southern Bahia, whereas the 50 haplotypes of the 54 individuals of the southern lineage all occurred at localities in Espírito Santo (north and south of the Rio Doce) and São Paulo (Table 1), and were separated by at least 30 mutational steps. Pairwise distance differences showed no gene flow between northern (BA) and southern (ES and SP) populations, and was confirmed by the high $\Phi_{\mathrm{ST}}$ values between BA/ES and SP populations (Table 2; $\Phi_{\mathrm{ST}}>0.63790, \mathrm{p}<0.05$ ). The phylogenetic tree topology and haplotype network agreed with the clustering of the northern and southern lineages observed in the maximum parsimony analysis presented by Nogueira and $\mathrm{Fa}-$ gundes (2008).

Akodon cursor had a significant population genetic structure of $\Phi_{\mathrm{ST}}=0.51$, and AMOVA, which was used to assess whether the Rio Doce influenced this group division (Table 2), showed that this river did not affect formation of the northern and southern lineages.

The pattern of phylogeographical groups observed in A. cursor could be limited by geographical landmarks, such as the Rio Doce basin, as observed in other mammals (Mustrangi and Patton, 1997; Costa et al., 2000), geckos (Pellegrino et al., 2005) and birds (Cabanne et al., 2007), although the splitting times among clades do not suggest a 
common temporal origin for these patterns (Cabanne et al., 2007). However, since the northern populations in Espírito Santo (Águia Branca and Governador Lindenberg) are located north of the Rio Doce, the network data supported the AMOVA results, i.e., that the Rio Doce does not play an important role in the divergence of $A$. cursor lineages and therefore that this geographical barrier should not be considered as the main cause of the breakage in the dispersion of these rodents, contrary to the proposal by Nogueira and Fagundes (2008).

Additional network analysis showed that all five haplotypes from Iguape (São Paulo) grouped as a monophyletic clade (Figure 1). Despite the generally low divergence between southern (ES and SP) populations, $\Phi_{\mathrm{ST}}$ analyses involving the Iguape (SP) and Águia Branca or Governador Lindenberg (ES) populations showed high divergence (Table 2).

Although this was no evidence of previous fragmentation in populations from São Paulo, this apparent "monophyly" may reflect either the lack of sampling of intermediate populations (including Rio de Janeiro state, for example) or the fact that the SP and ES populations are geographically far $(\sim 1000 \mathrm{~km})$ from each other in the southern lineage. These observations suggest that isolation by geographical distance and the history of vicariance (geographical location) could play an important role in shaping the population genetic structure of the southern lineage, including populations from São Paulo and northern Espírito Santo.

It is well-known that sampling the extremes of a population distributed as cline can yield spurious evidence of vicariance. The data for Águia Branca and Governador Lindenberg provide further evidence of this potential isolation by distance and support the conclusion that in the geographically complex Atlantic Forest it is unlikely that forest refugia or barrier hypotheses alone will account for general patterns of lineage diversification (Thomé et al., 2010). However, testing the isolation by distance mechanism requires further investigation.

Specimens with karyotypes $2 \mathrm{n}=14$ and 15 were distributed across all haplotype network branches (Table 1 and Figure 1), thus indicating that karyological data are not associated with lineage diversification, a conclusion that corroborate previous studies in A. cursor (Nogueira and Fagundes, 2008).

In conclusion, our data do not support a primary influence of the Rio Doce as a putative barrier in shaping the divergence between the two main mitochondrial lineages of A. cursor in the southeastern Atlantic forest. Rather, the data raise questions about the influence of isolation by geographical distance in modeling the phylogeographical structure of the southern lineage of A. cursor. However,

Table 2 - Genetic structure of the A. cursor populations. Upper half of table: pairwise $\Phi_{\mathrm{ST}}$ (genetic differentiation between populations). Lower half of table: Analysis of molecular variance (AMOVA) to test two hypothetical scenarios for the partitioning of genetic variation using the fixation indices among groups (Фct), among populations within groups ( $\Phi \mathrm{sc})$ and within populations $(\Phi s t)$. Significant p-values $(\mathrm{p}<0.05)$ are highlighted in bold. UNA (Bahia) was used to polarize the analysis and represent the northern lineage in A. cursor (see Figure 1).

\begin{tabular}{|c|c|c|c|c|c|c|c|c|c|c|c|}
\hline \multicolumn{12}{|c|}{$\Phi_{\mathrm{ST}}$} \\
\hline & \multicolumn{2}{|c|}{ UNA } & $\mathrm{AGU}$ & GOV & STA & CAR & CAS & DOM & VIA & IBI & IGU \\
\hline UNA & \multicolumn{11}{|c|}{-} \\
\hline $\mathrm{AGU}$ & \multicolumn{2}{|c|}{0.71086} & - & & & & & & & & \\
\hline GOV & \multicolumn{2}{|c|}{0.67690} & 0.58140 & - & & & & & & & \\
\hline STA & \multicolumn{2}{|c|}{0.69294} & 0.67446 & 0.62796 & - & & & & & & \\
\hline CAR & \multicolumn{2}{|c|}{0.63790} & 0.50794 & 0.34211 & 0.25244 & - & & & & & \\
\hline CAS & \multicolumn{2}{|c|}{0.64701} & 0.51471 & 0.33058 & 0.22456 & -0.16505 & - & & & & \\
\hline DOM & \multicolumn{2}{|c|}{0.70184} & 0.62098 & 0.52967 & 0.11715 & 0.04865 & 0.01356 & - & & & \\
\hline VIA & \multicolumn{2}{|c|}{0.68291} & 0.50366 & 0.40244 & 0.18418 & 0.15387 & 0.12047 & 0.11387 & - & & \\
\hline IBI & \multicolumn{2}{|c|}{0.65205} & 0.43124 & 0.29640 & 0.11581 & -0.01637 & -0.03754 & 0.03043 & 0.15155 & - & \\
\hline IGU & \multicolumn{2}{|c|}{0.73379} & 0.71739 & 0.71412 & 0.53991 & 0.48250 & 0.42399 & 0.47138 & 0.37011 & 0.29417 & - \\
\hline \multicolumn{12}{|c|}{ AMOVA } \\
\hline \multirow{2}{*}{\multicolumn{2}{|c|}{ Hypothesis }} & \multirow{2}{*}{\multicolumn{3}{|c|}{ Group feature }} & \multirow{2}{*}{\multicolumn{3}{|c|}{ Group composition }} & \multicolumn{3}{|c|}{ Porcentage of variation } & Fixation index \\
\hline & & & & & & & & $\Phi c t$ & $\Phi$ sc & Фst & \\
\hline \multirow{2}{*}{\multicolumn{2}{|c|}{$\begin{array}{l}\text { Rio Doce influ- } \\
\text { ences group subdi- } \\
\text { vision }\end{array}$}} & \multirow{2}{*}{\multicolumn{3}{|c|}{$\begin{array}{l}\text { Outgroup and populations north } \\
\text { of the river } \\
\text { Populations south of the river }\end{array}$}} & \multicolumn{3}{|c|}{ UNA, ABR, GOV } & \multirow[t]{2}{*}{37.68} & 23.90 & 38.40 & 61.59 \\
\hline & & & & & STE, CAR, & IA, DOM, & S, IBI, IGU & & & & \\
\hline \multirow{2}{*}{\multicolumn{2}{|c|}{$\begin{array}{l}\text { Rio Doce does not } \\
\text { influence group } \\
\text { subdivision }\end{array}$}} & \multirow{2}{*}{\multicolumn{3}{|c|}{$\begin{array}{l}\text { Outgroup, representing northern } \\
\text { lineage } \\
\text { Southern lineage }\end{array}$}} & UNA & & & \multirow[t]{2}{*}{62.51} & 9.88 & 27.61 & 72.39 \\
\hline & & & & & $\begin{array}{l}\text { ABR, GOV } \\
\text { IBI, IGU }\end{array}$ & TE, CAR, & A, DOM, C & & & & \\
\hline
\end{tabular}


there is uncertainty about effectiveness of the processes involved, and sampling on a wider scale is necessary to assess the importance of distinct isolation mechanisms.

\section{Acknowledgments}

The authors thank Y. Yonenaga-Yassuda (USP), M. Passamani (UFLA), R. Moura (UFMG), and Y. Leite, L. Costa, I. Pinto, L. Baião and R. Paresque (UFES) for collecting specimens and/or donating tissue samples for this study. This work was sponsored by Fundação de Apoio à Ciência e Tecnologia do Espírito Santo (FAPES), Fundo de Apoio à Ciência e Tecnologia do Município de Vitória (FACITEC), Critical Ecosystem Partnership Fund (CEPF) and Programa Taxonomia of Conselho Nacional de Desenvolvimento Científico e Tecnológico (CNPq). VHC was sponsored by a CNPq undergraduate scholarship and SRL by a FAPES PhD scholarship. We also thank the two anonymous reviewers and the editor-in-chief for constructive suggestions on earlier versions of the manuscript.

\section{References}

Bandelt HJ, Forster P and Röhl A (1999) Median-joining networks for inferring intraspecific phylogenies. Mol Biol Evol 16:37-48.

Bruford MW, Hanotte O, Brookfield JFY and Burke T (1992) Single-locus and multilocus DNA fingerprinting. In: Hoelzel AR (ed) Molecular Genetic Analyses of Populations - A Practical Approach. IRL Press, Oxford, pp 225-269.

Cabanne GS, Santos FR and Miyaki CY (2007) Phylogeography of Xiphorhynchus fuscus (Passeriformes, Dendrocolaptidae): Vicariance and recent demographic expansion in southern Atlantic forest. Biol J Linn Soc Lond 91:73-84.

Carnaval AC and Moritz C (2008) Historical climate modeling predicts patterns of current biodiversity in the Brazilian Atlantic forest. J Biogeogr 35:1187-1201.

Costa LP, Leite YL, Fonseca GAB and Fonseca MT (2000) Biogeography of South American forest mammals: Endemism and diversity in the Atlantic forest. Biotropica 32:872-881.

Excoffier L, Smouse P and Quattro J (1992) Analysis of molecular variance inferred from metric distances among DNA haplotypes: Application to human mitochondrial DNA restriction data. Genetics 131:479-491.

Excoffier LG, Laval G and Schneider S (2005) Arlequin v. 3.0: An integrated software package for population genetics data analysis. Evol Bioinform Online 1:47-50.

Fagundes V, Christoff AU and Yonenaga-Yassuda Y (1998) Extraordinary chromosomal polymorphism with 28 different karyotypes in the neotropical species Akodon cursor (Muridae, Sigmodontinae), one of the smallest diploid number in rodents $(2 n=16,15$ and 14). Hereditas 129:263-274.

Felsenstein J (1985) Confidence limits on phylogenies: An approach using the bootstrap. Evolution 39:783-791.

Geise L, Smith MF and Patton JL (2001) Diversification in the genus Akodon (Rodentia, Sigmodontinae) in southeastern South America: Mitochondrial DNA sequence analysis. J Mammal 82:92-101.
Grant WS and Bowen BW (1998) Shallow population histories in deep evolutionary lineages of marine fishes: Insights from sardines and anchovies and lessons for conservation. Genetics 89:415-426.

Gusmão Câmara I (2003) Brief history of conservation in the Atlantic forest. In: Galindo-Leal C and Gusmão Câmara I (eds) The State of the Hotspots: The Atlantic Forest. Island Press, Washington DC, pp 31-42.

Hall TA (1999) BioEdit: A user-friendly biological sequence alignment editor and analysis program for Windows 95/98/NT. Nucleic Acids Symp Ser 41:95-98.

Hudson RR, Slatkin M and Maddison WP (1992) Estimation of levels of gene flow from DNA sequence data. Genetics 132:583-589.

Moritz C, Patton JL, Schneider CJ and Smith TB (2000) Diversification of rainforest faunas: An integrated molecular approach. Annu Rev Ecol Syst 31:533-563.

Musser GG and Carleton MD (2005) Family Muridae. In: Wilson DE and Reeder DM (eds) Mammal Species of the World: A Taxonomic and Geographic Reference. Smithsonian Institution, Washington DC, pp 1189-1531.

Mustrangi MA and Patton JL (1997) Phylogeography and systematics of the slender mouse opossum Marmosops (Marsupialia, Didelphidae). Zoology. v. 130. University of California Press, Berkeley, 86 pp.

Nei M (1987) Molecular Evolutionary Genetics. Columbia University Press, New York, 512 pp.

Nogueira CDA and Fagundes V (2008) Akodon cursor Winge, 1887 (Rodentia, Sigmodontinae): One or two species? New evidences based on molecular data. Zootaxa 1768:41-51.

Pellegrino KCM, Rodrigues MT, Waite AN, Morando M, Yassuda YY and Sites JW (2005) Phylogeography and species limits in the Gymnodactylus darwinii complex (Gekkonidae, Squamata): Genetic structure coincides with river system in the Brazilian Atlantic Forest. Biol J Linn Soc Lond $85: 13-26$

Posada D and Crandall KA (1998) Modeltest: Testing the model of DNA substitution. Bioinformatics 14:817-818.

Rodrigues MT (2005) The conservation of Brazilian reptiles: Challenges for a megadiverse country. Conserv Biol 19:659-664.

Smith MF and Patton JL (1993) The diversification of South American murid rodents: Evidence from mitochondrial DNA sequence data for the akodontine tribe. Biol J Linn Soc Lond 50:149-177.

Swofford DL (2003) PAUP* Phylogenetics Analysis Using Parsimony (*and Other Methods) v. 4. Sinauer Associates, Sunderland.

Tamura K, Dudley J, Nei M and Kumar S (2007) MEGA4: Molecular Evolutionary Genetics Analysis (MEGA) software v. 4.0. Mol Biol Evol 24:1596-1599.

Thomé MTC, Zamudio KR, Giovanelli JGR, Haddad CFB, Baldissera Jr FA and Alexandrino J (2010) Phylogeography of endemic toads and post-Pliocene persistence of the Brazilian Atlantic Forest. Mol Phylogenet Evol 55:1018-1031.

Associate Editor: Fábio de Melo Sene

License information: This is an open-access article distributed under the terms of the Creative Commons Attribution License, which permits unrestricted use, distribution, and reproduction in any medium, provided the original work is properly cited. 